Article

\title{
Climate Extremes and Their Impacts on Interannual Vegetation Variabilities: A Case Study in Hubei Province of Central China
}

\author{
Weizhe Chen ${ }^{1}(\mathbb{D})$, Chunju Huang ${ }^{1,2, *(\mathbb{D})}$, Lunche Wang ${ }^{2}$ (D) and Dongmei $\mathrm{Li}^{2,3}$ \\ 1 State Key Laboratory of Biogeology and Environmental Geology, School of Earth Sciences, \\ China University of Geosciences, Wuhan 430074, China; wzchen@cug.edu.cn \\ 2 Laboratory of Critical Zone Evolution, School of Earth Sciences, China University of Geosciences, \\ Wuhan 430074, China; wang@cug.edu.cn (L.W.); dianqijiaojiansearch@gmail.com (D.L.) \\ 3 Xinjiang Institute of the Land Source Planning, Urumchi 830000, China \\ * Correspondence: huangcj@cug.edu.cn
}

Received: 11 February 2018; Accepted: 18 March 2018; Published: 19 March 2018

\begin{abstract}
As the frequency and intensity of climate extremes are likely to be substantially modified in upcoming decades due to climate warming, an evaluation of the response of interannual vegetation variabilities to climate extremes is imperative. This study comprehensively analyzed the spatio-temporal variabilities of 21 temperature and precipitation indices across Hubei Province in Central China based on daily meteorological records for the period 1961-2015. To quantify the sensitivity of the vegetation to climate indices in the study area, we correlated climate indices with three vegetation indicators: leaf area index, normalized difference vegetation index, and gross primary productivity. The results indicated that warm-related indices exerted considerable increasing trends, especially for summer days at a rate of 0.35 days year ${ }^{-1}(p<0.01)$. In addition, the trends of 18 indices during 1982-2015 were larger than those during 1961-2015, indicating accelerated climate changes in Hubei Province. Spatially, extreme precipitation showed increases in the eastern regions of the study area and decreases in the western regions. Correlation analyses revealed that warm anomalies of the Atlantic Multidecadal Oscillation resulted in extreme warm conditions and extreme precipitation in the study area. Stepwise linear regression analyses identified three temperature indices and three precipitation indices, which were mostly correlated with the three ecosystem variables at the site scale. Further multiple regressions demonstrated the main negative impacts caused by frost days, warm spell duration, extremely heavy precipitation, and consecutive dry days on the terrestrial ecosystem in Hubei Province. Our study provides an improved understanding of the effects of climate extremes on terrestrial ecosystems and can also offer a basis for the management of mitigating damage from climate extremes.
\end{abstract}

Keywords: multiple climate indices; ecological response; temporal variability; multiple linear regression; Central China

\section{Introduction}

Global mean surface temperature warmed by approximately $0.72{ }^{\circ} \mathrm{C}$ during the period 1951-2012 [1]. The impacts of climate change on ecosystems have drawn attention from researchers over the past decade. However, global climate change studies focused mainly on changes in mean values for decades by using observational temperature and precipitation data [2,3]. As the issue of climate change became more prominent, climate extremes have received many attentions in recent decades as they tend to be more sensitive to climate change than the mean climate [4]. In addition, the importance of climate extremes and variability is now clear in impact studies. Extreme climate 
events (e.g., a drought event across Europe in 2003 [5]) can result in disasters by interacting with exposed and vulnerable human and natural systems [6,7]. To support these adaptions, there is a great demand for evaluating the climate extremes [8] and quantifying the impact of climate change on ecosystems variables $[9,10]$ at regional scales.

Efforts from the Expert Team on Climate Change Detection and Indices (ETCCDI) have helped to standardize the definitions and calculations of climate extreme indices and facilitate the studies on climate extremes [11]. Based on the same index definitions from the ETCCDI, recent studies found that many climate extremes have occurred more frequently under warmer conditions across the globe for the past decades $[2,12,13]$, especially temperature extremes associated with warming (e.g., hot days). Climate extremes have also been extensively studied within China, and significant changes have been detected [14-16]. For example, Xiao et al. [15] showed that the summer rainfall intensity has increased by approximately $11.2 \%$ on average in China with continuous hourly gauge records during 1971-2013 from 721 weather stations. Trends in warm and hot days increased more rapidly after the early 1980s than before in most regions of China [14]. For Central China, cold-related indices presented significant downtrends, while warm-related indices showed significant increasing trends during 1960-2012 in the Yangtze River Basin [17]. In Hunan Province in Central China, the statistically significant changes in extreme temperature indices have been observed at more stations than changes in extreme precipitation indices [18]. Model studies implied that many climate extremes would show an increasing tendency in the coming decades [19-21]. Increases in summer days and extreme wet events are projected in Central China based on 14 global climate models in the Coupled Model Intercomparison Project Phase 5 (CMIP5) [22]. This further emphasizes that more quantitative evaluations of the sensitivities of regional ecosystems to different climate extremes is imperative for future ecological and agricultural management and projection.

Extreme climate events have inevitably led to vegetation loss because of the strong relationship between the climate system and the ecosystem [22-24]. For example, the extreme heat and drought in 2003 caused a $30 \%$ reduction in gross primary productivity and resulted in a strong anomalous net source of carbon dioxide over Europe [5]. The negative impacts of climate extremes on natural ecosystems and agriculture have also been partly investigated in China [25-27]. The hundred-year return heat wave and drought in the summer of 2013 significantly reduced the vegetation index and gross primary production, which produced the largest negative crop yield anomaly since 1960 in southern China [25]. A spatio-temporal evaluation of the damage from heavy rain and floods in China exhibited that the agricultural area that was covered and affected by floods exhibited a significant increasing trend from 1950 to 2013, especially for the Yangtze River Basin [28]. However, these studies focused on a few climate extreme indices or events and did not analyze the response of different ecosystem variables to a full range of extremes indices systematically. Furthermore, it is essential to quantify the different contributions of climate indices on ecosystem variables over time [29], as exposure and vulnerability vary across temporal and spatial scales and particularly depend on local geographic and environmental factors $[6,30,31]$.

Sensitivity and vulnerability assessments in China and across the globe suggested that the ecological response to climate variability is not the same if the research area is different [26,32]. This spatial variation emphasizes that it is necessary to conduct more comprehensive investigations at regional scales. This study focused on the province of Hubei in Central China. Hubei Province has also undergone significant climate changes and frequent climate extremes. Liu et al. [33] found that the frost event in January and February of 2008 produced an abrupt decrease in net primary productivity in forest and grass ecosystems in Central China. Correlation analyses exhibited a stronger effect from air temperature than from precipitation on leaf area index and vegetation productivity in this region $[34,35]$. However, systematic analyses of sensitivities of ecosystems to a full range of extremes indices are still scarce in the literature $[34,36]$. Therefore, the goal of this study is to diagnose local climate extremes and their impacts on vegetation. There are three major objectives: (1) to evaluate the temporal variabilities of climate extremes in Hubei Province by utilizing a daily meteorological 
data; (2) to identify the main climatic factors that impact ecosystem variables among 21 climate indices; and (3) to quantify the contribution rates of these main climatic factors on vegetation. The results are expected to improve our knowledge on regional ecological responses to climate variabilities and further support decision-making for the adaptation to extreme climate events.

\section{Data and Methods}

\subsection{Study Area}

Hubei Province, situated between $29^{\circ} 05^{\prime}-33^{\circ} 20^{\prime} \mathrm{N}$ and $108^{\circ} 21^{\prime}-116^{\circ} 07^{\prime} \mathrm{E}$ with an area of $1.859 \times 10^{5} \mathrm{~km}^{2}$ (Figure 1), is regarded as the political, economic and cultural center of Central China [36]. The elevation in this area has a clear descendant gradient from west to southeast. The province belongs to the north subtropical zone of humid monsoon climate, with a mean annual temperature of $15-17^{\circ} \mathrm{C}$ and mean annual precipitation of $1100-1300 \mathrm{~mm}$ [34]. Seasonal climate is characterized by hot and humid summers and cold and dry autumns and winters [37,38]. Long-term harmonized meteorological records make it possible to comprehensively study the spatial distribution and temporal variability of climate change within the province.

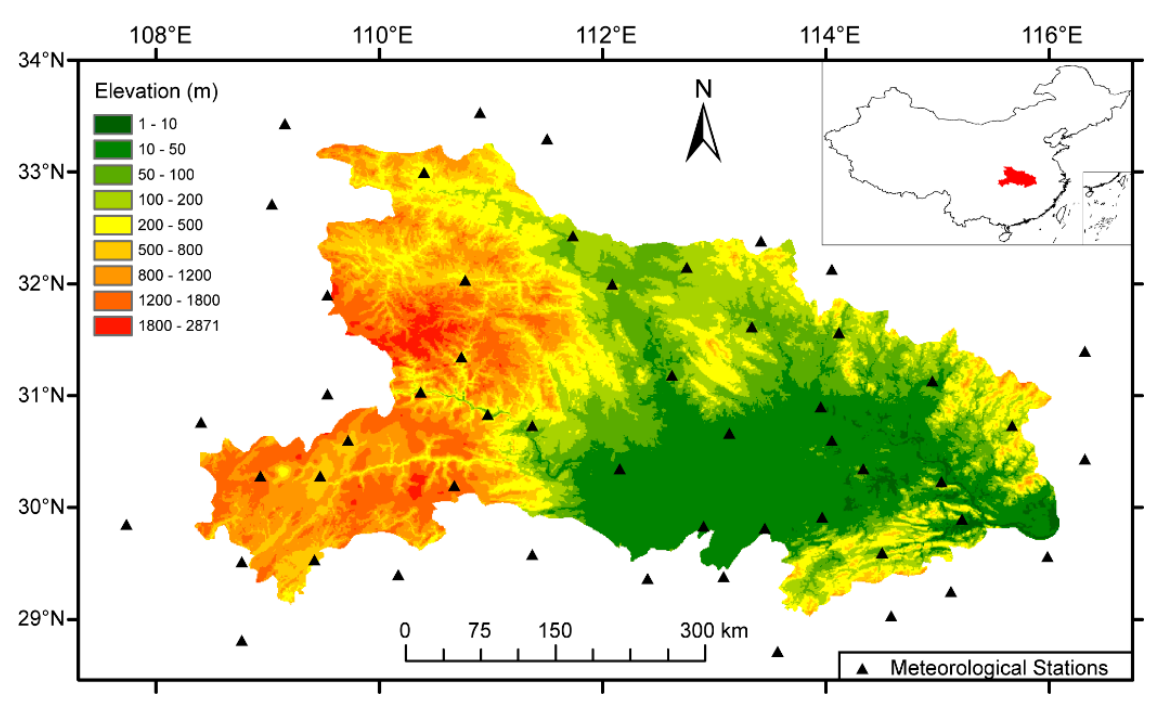

Figure 1. Location map of Hubei Province with elevation. The dark triangles denote the 52 meteorological stations used in this study.

\subsection{Data Collection}

Time series of observed daily maximum, minimum, and mean air temperature (TX, TN, and Ta, respectively) and daily total precipitation (P) from meteorological stations were obtained from the China Meteorological Administration (CMA) [39]. To cover the whole study area, a 60-km buffer from the edge of the province boundary was used to determine the meteorological stations used in this study. Then, according to the criteria that the series length should cover 1961-2015 and the missing data should be no more than 1\% in every year at each station, data from 52 stations were ultimately selected for analyses, which included 30 stations within the study area and 22 around the study area (Figure 1). To clarify the relationship between indices of climatic extremes and large-scale circulation modes of climate variability, time series of monthly atmospheric and oceanic climate indices, including Multivariate ENSO Index (MEI), Pacific Decadal Oscillation (PDO) and Atlantic Multidecadal Oscillation (AMO), were collected from Earth System Research Laboratory, National Oceanic and Atmospheric Administration (NOAA) [40].

Vegetation variabilities in Hubei Province were evaluated with long-term global mapping leaf area index (LAI) product (GLOBMAP LAI Version 3) [41] and third-generation normalized 
difference vegetation index product (NDVI 3g.v1) [42]. The GLOBMAP LAI product was generated by quantitative fusion of the Moderate Resolution Imaging Spectroradiometer (MODIS) and the historical Advanced Very High Resolution Radiometer (AVHRR) data [43]. The pixel-level relationships between the AVHRR and the MODIS LAI were first established during the overlapping period 2000-2006 and used to estimate the AVHRR LAI back to 1981. Consequently, the long-term LAI series was constructed by a combination of the AVHRR LAI (1981-2000) and the MODIS LAI (2000-2016), which provided a global LAI dataset at a 15-day temporal resolution and an 8-km spatial resolution from 1981 to 2016. The NDVI data was derived from the new Global Inventory Modeling and Mapping Studies (GIMMS) [44], which can be found at the NASA Earth Exchange (NEX). This NDVI data was produced from AVHRR instruments that extended from 1981 to the present. In addition, this data has been widely used in previous land surface studies as a spatio-temporal indicator for vegetation activity [45-47].

A new gross primary productivity (GPP) data, with $0.1^{\circ}$ spatial resolution and monthly temporal frequency over China, was obtained from Yao et al. [35], where a machine learning algorithm with eddy flux measurements was applied to 40 sites in China and its surrounding countries. The high-resolution GPP data can successfully capture the spatio-temporal variations of the GPP observed at the flux sites, including validation flux site data that were not put in training of model tree ensemble (MTE). All of the gridded datasets were first composited to annual temporal resolution and then aggregated to $0.05^{\circ} \times 0.05^{\circ}$ spatial resolution using bilinear interpolation.

Brief information for all data used in this research is listed in Table 1.

Table 1. Summary of the data used in this study.

\begin{tabular}{cccccc}
\hline Data & $\begin{array}{c}\text { Temporal } \\
\text { Coverage }\end{array}$ & $\begin{array}{c}\text { Temporal } \\
\text { Resolution }\end{array}$ & $\begin{array}{c}\text { Spatial } \\
\text { Coverage }\end{array}$ & $\begin{array}{c}\text { Spatial } \\
\text { Resolution }\end{array}$ & Source \\
\hline TX/TN/Ta & $1961-2015$ & Daily & Whole China & 52 sites & CMA \\
P & $1961-2015$ & Daily & Whole China & 52 sites & CMA \\
MEI/PDO/AMO & $1961-2015$ & Monthly & - & - & NOAA \\
LAI & $1982-2015$ & 8 days/half month & Globe & $8 \mathrm{~km}$ & GLOBMAP \\
NDVI & $1982-2015$ & 15 days & Globe & $1 / 12^{\circ}$ & GIMMS \\
GPP & $1982-2015$ & Monthly & Whole China & $0.1^{\circ}$ & Yao et al. [35] \\
\hline
\end{tabular}

\subsection{Definitions and Calculations of the Climate Indices}

In scientific literature, climate extremes are based on the use of so-called "extreme indices", which can either be based on the probability of occurrence of given quantities or on threshold exceedances [6]. As a result, there are a variety of definitions for climate extremes [14,48]. The ETCCDI has developed and recommended 27 core climate indices [12], which have been widely used $[2,4,22,48,49]$ and adopted by the Fifth Assessment Report of Intergovernmental Panel on Climate Change [1]. Seven monthly indices of the recommended 27 climate indices were excluded, and one additional index of hot days (SU35) was included. Hence, a total of 21 indices (Table 2) were therefore calculated with the RClimDex software package [50,51] in the R-project 3.3.2 (Free Software Foundation: Boston, MA, USA), which can automatically check the quality of original daily data.

Table 2. The definitions of the 21 climate indices used in this study.

\begin{tabular}{ccccc}
\hline ID & Indicators & Definitions & Units \\
\hline FD0 & Frost days & Annual count when $\mathrm{TN}<0{ }^{\circ} \mathrm{C}$ & Days \\
\hline SU25 & Summer days & Annual count when $\mathrm{TX}>25^{\circ} \mathrm{C}$ & Days \\
\hline SU35 & Hot days & Annual count when $\mathrm{TX}>35^{\circ} \mathrm{C}$ & Days \\
\hline ID0 & Ice days & Annual count when $\mathrm{TX}<0{ }^{\circ} \mathrm{C}$ & Days \\
\hline TR20 & Tropical nights & Annual count when TN $>20^{\circ} \mathrm{C}$ & Days \\
\hline GSL & Growing season length & $\begin{array}{c}\text { Annual count between first span of at least } 6 \text { days with a daily } \\
\text { mean temperature TG }>5{ }^{\circ} \mathrm{C} \text { and first span after } 1 \text { July of } 6 \text { days } \\
\text { with a TG }<5{ }^{\circ} \mathrm{C}\end{array}$ & Days \\
\hline
\end{tabular}


Table 2. Cont.

\begin{tabular}{|c|c|c|c|}
\hline ID & Indicators & Definitions & Units \\
\hline TN10p & Cool nights & Percentage of days when $\mathrm{TN}<10$ th percentile & Days \\
\hline TX10p & Cool days & Percentage of days when $\mathrm{TX}<10$ th percentile & Days \\
\hline TN90p & Warm nights & Percentage of days when TN $>90$ th percentile & Days \\
\hline TX90p & Warm days & Percentage of days when $\mathrm{TX}>90$ th percentile & Days \\
\hline WSDI & Warm spell duration indicator & $\begin{array}{l}\text { Annual count of days with at least } 6 \text { consecutive days when } \\
\text { TX }>90 \text { th percentile }\end{array}$ & Days \\
\hline CSDI & Cold spell duration indicator & $\begin{array}{l}\text { Annual count of days with at least } 6 \text { consecutive days when } \\
\qquad \mathrm{TN}<10 \text { th percentile }\end{array}$ & Days \\
\hline SDII & Simple precipitation intensity index & $\begin{array}{l}\text { Annual total precipitation divided by the number of wet days } \\
\text { (defined as daily } p \geq 1.0 \mathrm{~mm} \text { ) in the year }\end{array}$ & $\mathrm{mm}_{\text {days }}{ }^{-1}$ \\
\hline R10 & Moderate precipitation days & Annual count of days when daily $p \geq 10 \mathrm{~mm}$ & Days \\
\hline R20 & Heavy precipitation days & Annual count of days when daily $p \geq 20 \mathrm{~mm}$ & Days \\
\hline R50 & Extremely heavy precipitation days & Annual count of days when daily $p \geq 50 \mathrm{~mm}$ & Days \\
\hline CDD & Consecutive dry days & Maximum number of consecutive days with a daily $p<1 \mathrm{~mm}$ & Days \\
\hline CWD & Consecutive wet days & Maximum number of consecutive days with a daily $p \geq 1 \mathrm{~mm}$ & Days \\
\hline R95p & Very wet days & Annual total $p$ when daily $p>95$ th percentile & $\mathrm{mm}$ \\
\hline R99p & Extremely wet days & Annual total $p$ when daily $p>99$ th percentile & $\mathrm{mm}$ \\
\hline PRCPTOT & Annual total wet-day precipitation & Annual total $p$ in wet days (daily $p \geq 1 \mathrm{~mm}$ ) & $\mathrm{mm}$ \\
\hline
\end{tabular}

\subsection{Multiple Linear Regression}

Multiple linear regression (MLR) is a widely used method for analyzing the correlations of climatic factors with variations in hydrological and ecosystem variables $[9,31,33,52,53]$. It is primarily utilized for examining the linear correlations between several independent variables and a single dependent variable. In addition, MLR depends on the least squares method, which is used to minimize the sum of squares of differences between actual and predicted values of the dependent variable.

In this study, an MLR was performed to quantify the relative contribution of the climate extremes to interannual variations in the ecosystem variables. The processing steps are mainly modified from Wang et al. [29]. Prior to applying the model, all independent variables and dependent variables were first normalized as follows:

$$
X_{i}=\frac{x_{i}-x_{\min }}{x_{\max }-x_{\min }}
$$

where $X_{i}$ represents normalized variable; $x_{i}$ represents the value of the detrended sequential data; and $x_{\min }$ and $x_{\max }$ represents the minimum and maximum values of the detrended sequential data, respectively. This processing eliminates the effects of dimension and enhances the signal of interannual variations in the original sequential data. Multiple regression was then performed, where individual normalized ecosystem variables were dependent variables and normalized climate indices were independent variables. The general formula of multiple regression is shown as follows:

$$
E I^{\prime}=\sum_{i=1}^{n} \beta_{i} X_{i}+\varepsilon
$$

where $E I^{\prime}$ represents individual normalized ecosystem variables; $X_{i}$ represents normalized predictors of climate indices; $\beta_{i}$ represents standardized regression coefficients which directly indicate the relative sensitivity of individual climate indices; $\varepsilon$ represents the regression constant; and $n$ represents the number of independent variable. In a stepwise multiple regression model, the $p$-value for an F-test of the change in the sum of squares for error (SSE), determines the removal and addition of the term in the model. Candidate variables from the 21 climate indices were selected for the model based on the 0.1 significance level. However, for an MLR, all of the selected variables were chosen to model the 
correlation between ecosystem and climate indices. Based on the regression coefficients of the MLR, a relative contribution rate $\left(\eta_{i}\right)$ of each predictor was expressed as:

$$
\eta_{i}=\frac{\left|\beta_{i}\right|}{\sum_{i=1}^{n}\left|\beta_{i}\right|}
$$

\subsection{Spatio-Temporal Analyses}

All trends in this study were calculated using a linear least square regression method. Climate indices for the entire Hubei Province were area-weighted average from 30 sites within the study area using the Thiessen polygon method [54]. As the main climate factors for ecosystems are not always stable over time $[28,29]$, the temporal evolution of the relative contribution rates of the selected climate indices was analyzed by conducting MLR with moving windows. A 10-year-width moving window is selected after considering the data length and the temporal stability of the contribution rate of drivers. Specifically, a MLR was performed during the periods of 1982-1991, 1983-1992 . . , 2006-2015.

\section{Results}

\subsection{Spatial Trends in the Climate Indices at the Site Scale}

Spatial variations of the trends in climate extremes for the 52 meteorological stations across Hubei Province are shown in Figure 2. Summer days (SU25) show increasing trends at almost all stations in Hubei Province and its surrounding areas. Spatially, the statistically significant increasing trends mainly vary between 0.3 and 0.5 days year $^{-1}$ at the 0.05 significance level, except for a few stations in the southwest regions, which have relatively higher elevations. Consequently, the warm-related indices of tropical nights (TR20) and WSDI also exhibit significant increasing trends, mainly in the eastern regions, with the ranges of $0.2-0.4$ days year $^{-1}$ and $0.1-0.4$ days year ${ }^{-1}$, respectively. Significant changes are shown at night, with increases during warm nights (TN90p) and decreases during cool nights (TN10p) at most stations. In contrast, changes during daytime (as expressed by warm days (TX90p) and cool days (TX10p)) are generally not significant at the 0.05 significance level. Trends in these indices at most stations are all consistent with climate warming, which is characterized by increases in warm-related indices and decreases in cold-related indices.

As for the precipitation indices, the number of stations with significant trends at the 0.05 significance level is generally less than that for temperature indices. Based on the spatial patterns of the trends in precipitation extremes for extremely heavy precipitation days (R50), very wet days (R95p) and extremely wet days (R99p), the eastern areas show increasing trends in extreme precipitation while western areas show the opposite. The difference between the western and eastern regions of the study area is also demonstrated by the moderate precipitation days (R10) and consecutive dry days (CDD) indices. This difference might relate to the increases in annual total wet-day precipitation (PRCPTOT) in the east and decreases in PRCPTOT in the west. The decline of wind speed across the globe and China $[55,56]$ is likely the key factor for the differences. As shown in Figure 1, there is a clear gradient in altitudes from the west to the east within the study area. As a result, decreased east wind speed in summer fails to bring moisture to the west of Hubei Province and consequently leads to increased precipitation in the east and decreased precipitation in the west. 

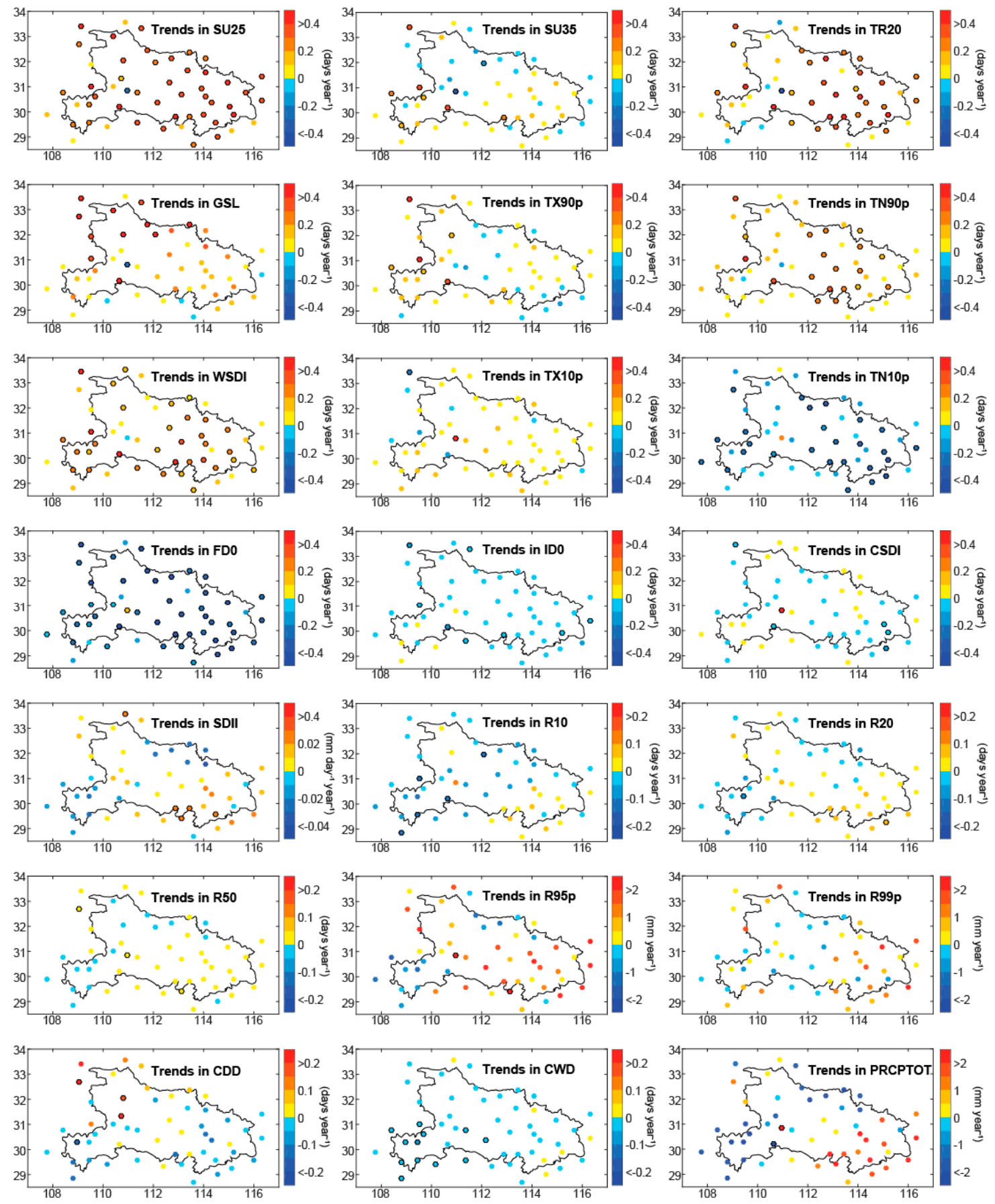

Figure 2. Temporal trends in temperature and precipitation indices from 1961 to 2015 at the 52 meteorological stations distributed across Hubei Province. The colored dots represent the magnitude of the trends, and the black outlines indicate the significance at the $p<0.05$ level.

\subsection{Spatial Patterns of the Ecosystem Variables in Hubei Province}

To evaluate the mean state and changes in the ecosystem in Hubei Province, three ecosystem indicators are chosen in this study (Figure 3). The spatial patterns of the mean values of the three ecosystem variables are generally consistent. All mean annual LAI, NDVI, and GPP show high values in the western regions and low values in the central-eastern regions, indicating increases along the latitudes. High values of LAI, NDVI, and GPP in the west range between $2.5-4 \mathrm{~m}^{2} \mathrm{~m}^{-2}, 0.5-0.7$ and 16-18 $\mathrm{gC} \mathrm{m}^{-2}$ year $^{-1}$, respectively. There are two possible reasons for this spatial pattern. On the one 
hand, the Shennongjia National Nature Reserve is located in the west, which has a high density of vegetation. On the other hand, the low ecosystem values may also result from human activities (e.g., cultivation and urbanization). For instance, the lowest values of LAI and NDVI are shown in Wuhan, which is the most urbanized city, and is also the capital city of Hubei Province.
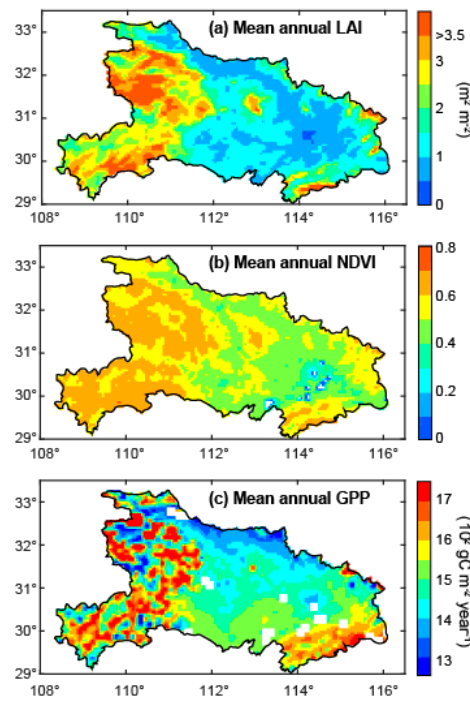
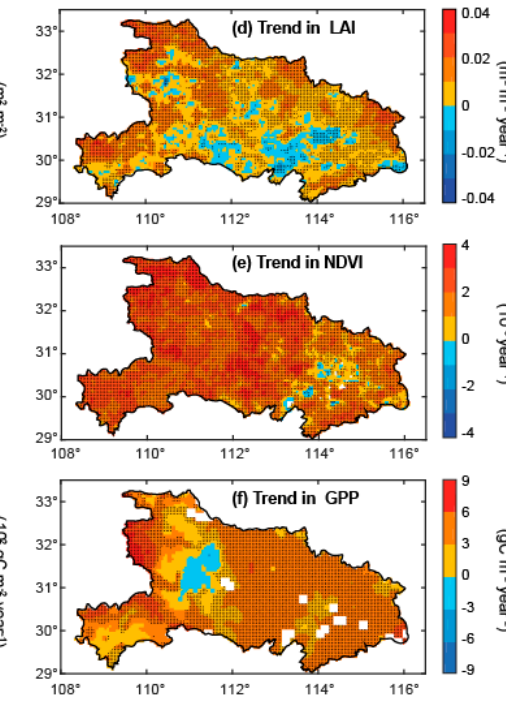
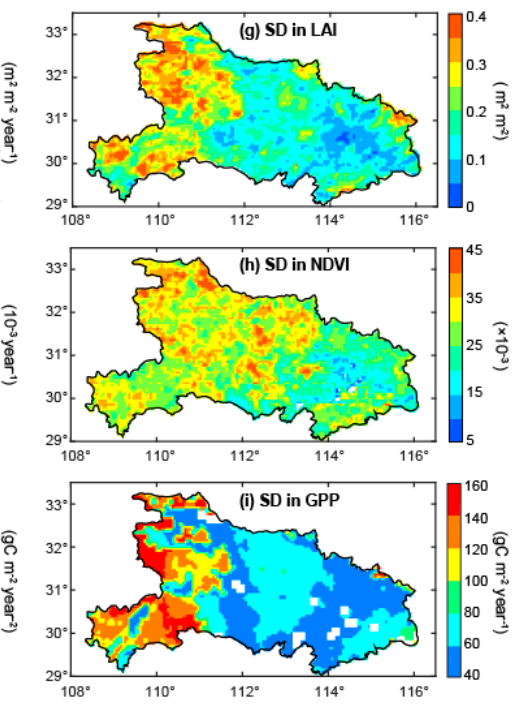

Figure 3. Spatial distribution of mean values $(\mathbf{a}-\mathbf{c})$, trends $(\mathbf{d}-\mathbf{f})$ and SDs $(\mathbf{g}-\mathbf{i})$ for LAI, NDVI, and GPP during 1982-2015. Black points indicate pixels where the trends are significant at the 0.05 significance level in panels $(\mathbf{d}-\mathbf{f})$.

Increases in LAI, NDVI, and GPP are overall significant $(p<0.05)$ for most pixels during 1982-2015. Slight and insignificant negative trends are only shown in some areas in the southern regions, central-eastern regions, and western regions of the study area for LAI, NDVI, and GPP, respectively. Since this study mainly focuses on the interannual variations in ecosystems, the standard deviations (SDs) of the three ecosystem variables are shown here, which are used to quantify the amount of variation in the temporal series data values. Generally, all three datasets exhibit a clear gradient from the west to the east, with high variabilities in the west and low variabilities in the east.

\subsection{Trends in the Climatic and Ecosystem Variables}

As a result of climate warming, the warm-related indices all exhibit increasing trends during 1961-2015, including SU25, SU35, TR20, growing season length (GSL), TX90p, TN90p, and warm spell duration indicator (WSDI) (Figure 4). The most significant increasing trend is observed in SU25 at 0.35 days year $^{-1}(p<0.01)$ for the period $1961-2015$ and 0.65 days year ${ }^{-1}(p<0.01)$ for the period 1982-2015, followed by TR20, GSL, and WSDI. This means that summer days have increased by approximately 22 days for the past three decades. In addition, increasing trends in SU25, SU35, TR20, GSL, TX90p, TN90p, and WSDI for the period 1982-2015 are revealed at rates of 0.65 days year y $^{-1}$ $(p<0.01), 0.34$ days year ${ }^{-1}(p<0.01), 0.34$ days year $^{-1}(p<0.01), 0.37$ days year $^{-1}, 0.24$ days year $^{-1}$,

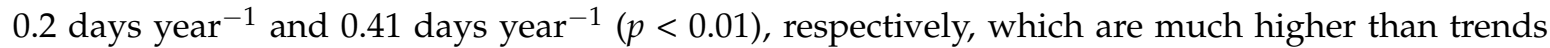
for 1961-2015. In contrast, the cold-related indices of frost days (FD0) and ice days (ID0) exhibit clear downtrends during 1961-2015 of -0.35 days year $^{-1}(p<0.01)$ and -0.03 days year ${ }^{-1}(p<0.1)$, respectively. It is worth mentioning that although ID0 has been low since the 1980s, it shows an extremely high value in 2008. This extreme cold event corresponds well with the snow disaster in the winter of 2008, which has also been specially investigated before [33]. This indicates that the results and methods for extracting the climate extremes in this study are reliable. 
There are generally no significant trends for all of the precipitation indices across Hubei Province during the past five decades (Figure 4), except for a significant downtrend in consecutive wet days (CWD) at a rate of -0.02 days year $^{-1}(p<0.1)$. However, trends in eight out of the nine precipitation indices during 1982-2015 are larger than those during 1961-2015. During 1982-2015, relatively remarkable trends are shown for R10, R95p, and PRCPTOT at -0.11 days year ${ }^{-1}$, $-1.23 \mathrm{~mm}_{\text {year }}{ }^{-1}$, and $-3.68 \mathrm{~mm}_{\text {year }}{ }^{-1}$, respectively. These results also clearly capture the extreme precipitation-induced flood in 1998, which is seen in the time series for R50, R95p, and R99p.
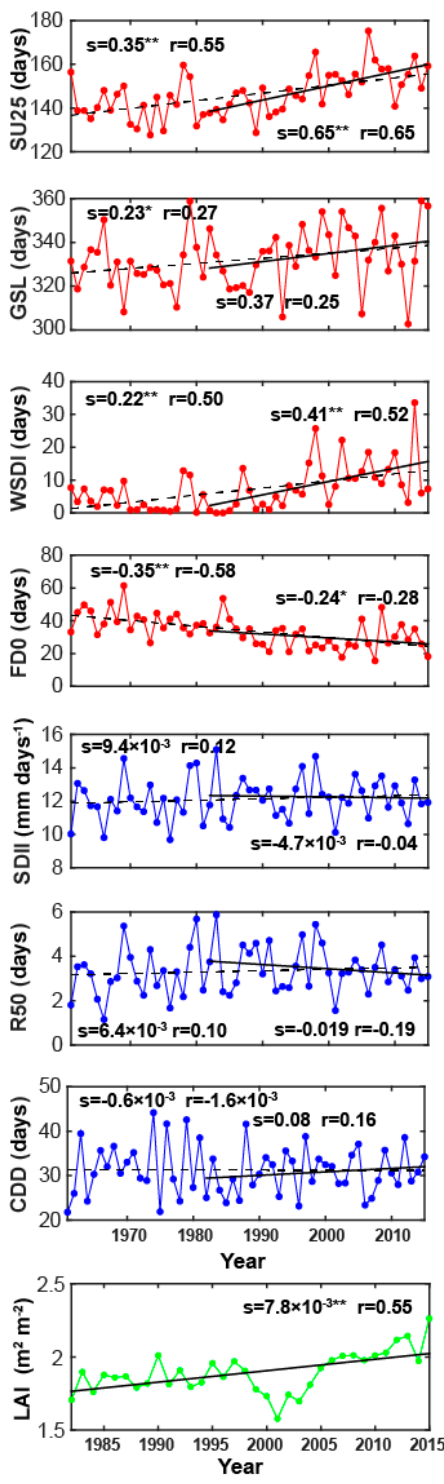
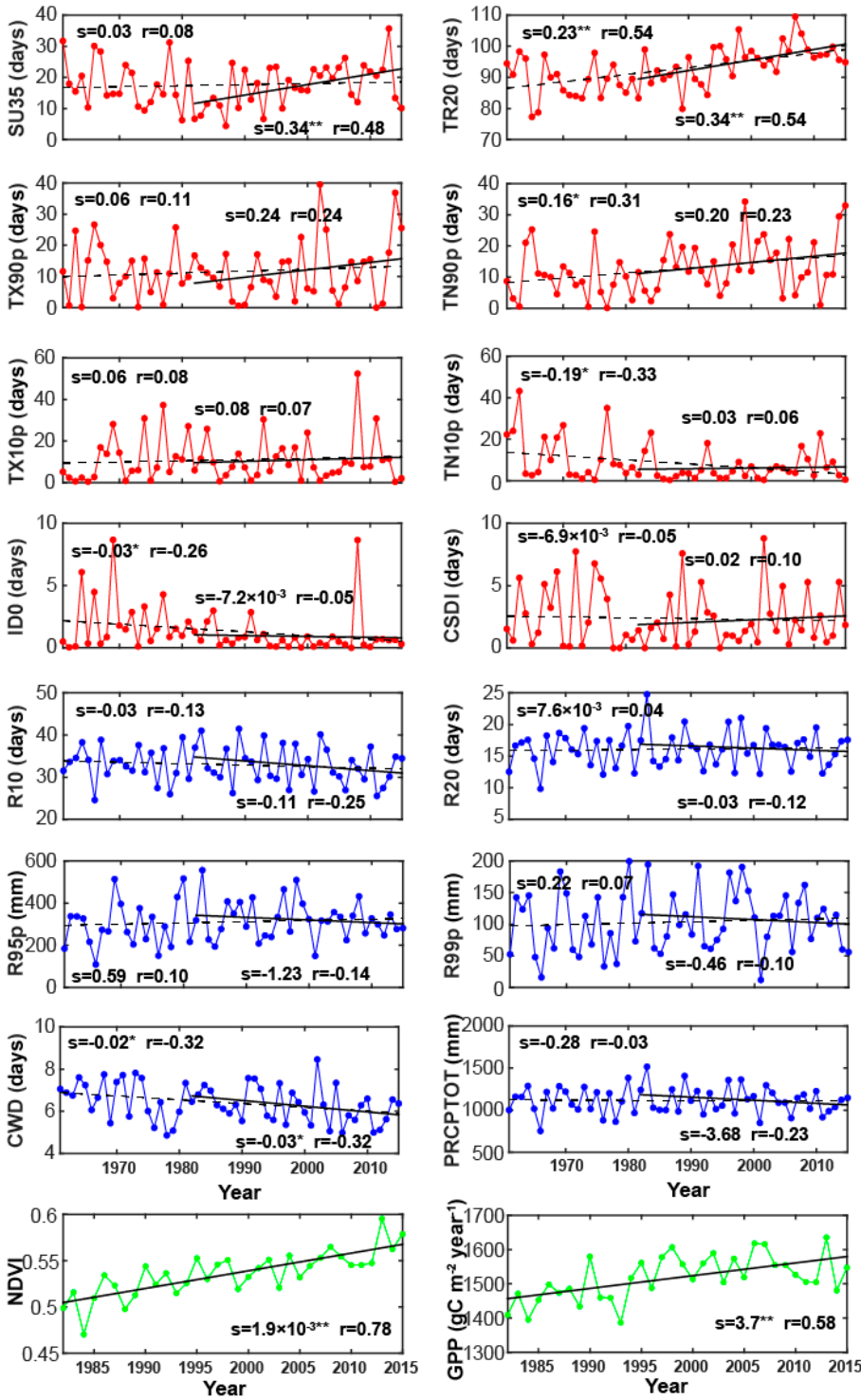

Figure 4. The temporal variations in temperature (red curves), precipitation (blue curves), and ecosystem (green curves) indicators in Hubei Province. In the legend, the letter s refers to the regression coefficient, and the letter $r$ refers to the correlation coefficient. For the temperature and precipitation indices, the regression coefficient on the left and right are for the periods 1961-2015 and 1982-2015, respectively. Significance levels are denoted as follows: ${ }^{*} p<0.1$ and ${ }^{* *} p<0.01$.

All three ecosystem indicators (i.e., LAI, NDVI, and GPP) for the whole study area show remarkable increases during 1982-2015 of $7.8 \times 10^{-3} \mathrm{~m}^{2} \mathrm{~m}^{-2}$ year $^{-1}(p<0.01), 1.9 \times 10^{-3}$ year $^{-1}$ $(p<0.01)$ and $3.7 \mathrm{gC} \mathrm{m}^{-2}$ year $^{-2}(p<0.01)$, respectively (Figure 4$)$. The trend in LAI in Hubei Province is close to the LAI trend in China $\left(7 \times 10^{-3} \mathrm{~m}^{2} \mathrm{~m}^{-2}\right.$ year $\left.{ }^{-1}\right)$ for the period 1982-2009 [57]. 
Based on five process-based ecosystem models, the greening trends of vegetation in China were mainly attributed to the rising atmospheric $\mathrm{CO}_{2}$ concentration and nitrogen deposition [57]. Previous studies also indicated that the impact of climate change on vegetation has large uncertainties in models [9], which emphasizes the importance to detect the impact of climate extremes on ecosystems using Earth observation data [7]. Temporal variations in vegetation indices are made up of trends and interannual variations. Interannual variations in ecosystems are mainly controlled by climate variability, which is supported by studies at the global scale [31,32] and for Hubei Province [34,58]. Since this study mainly focuses on interannual variations in vegetation, all the linear trends were removed before the regression analyses.

\subsection{Relative Sensitivity of the Ecosystem Variables to All 21 Climate Indices at the Site Scale}

Since not all these 21 climate indices were sensitive for the ecosystem variables, stepwise multiple regressions (see Section 2.4) were performed between the three ecosystem variables and all the 21 climate indices for the 30 stations within the study area in order to derive sensitive climate variables for vegetation in Hubei Province. The number of times that each climate index was chosen as a candidate variable in the stepwise multiple regressions for the three ecosystems and for all stations was regarded as the relative ecological importance of the corresponding climate index.

As shown in Table 3, the LAI, NDVI, and GPP were the most sensitive to SU35, SU25, and SU25, respectively, at sites scales. For the sum among the three ecosystem variables, SU25 was chosen 45 times during the stepwise multiple regressions, which ranked first among all of the climate indices. This means that the ecosystem variables in Hubei Province were mostly correlated with the SU25 index, followed by FD0 and WSDI temperature indices. Among the nine precipitation indices, simple precipitation intensity index (SDII), R50 and CDD had the greatest sensitivity for the ecosystem variables in Hubei Province. Consequently, these six climate indices were chosen for further study (i.e., the three temperature indices and the three precipitation indices). The selected indices covered hot days, cold days, extreme precipitation, and dry days, which frequently occurred in the study area and supposedly have significant impacts on interannual variations in the local ecosystem.

Table 3. The number of times that the corresponding climate index was chosen as the candidate variable when the stepwise linear regression was performed between the corresponding ecosystem variables and the 21 climate indices at 30 meteorological stations within the study area.

\begin{tabular}{ccccc}
\hline Indices & LAI & NDVI & GPP & Sum \\
\hline SU25 * & 7 & 14 & 24 & 45 \\
ID0 & 3 & 3 & 1 & 7 \\
TR20 & 6 & 0 & 4 & 10 \\
FD0 * & 5 & 3 & 11 & 19 \\
SU35 & 8 & 1 & 5 & 14 \\
GSL & 4 & 3 & 4 & 11 \\
TN10p & 1 & 3 & 5 & 9 \\
TX10p & 2 & 1 & 3 & 6 \\
TN90p & 1 & 4 & 5 & 10 \\
TX90p & 3 & 0 & 4 & 7 \\
WSDI * & 2 & 2 & 11 & 15 \\
CSDI & 3 & 2 & 2 & 7 \\
SDII * & 4 & 5 & 13 & 22 \\
R10 & 2 & 3 & 3 & 8 \\
R20 & 4 & 0 & 6 & 10 \\
R50 * & 0 & 6 & 7 & 13 \\
CDD * & 5 & 2 & 4 & 11 \\
CWD & 1 & 5 & 2 & 8 \\
R95p & 3 & 1 & 2 & 6 \\
R99p & 4 & 4 & 2 & 10 \\
PRCPTOT & 2 & 1 & 4 & 7
\end{tabular}

* The three most sensitive temperature indices and the three most sensitive precipitation indices are marked. 


\section{Discussion}

\subsection{Temporal Climatic Variations and Possible Connections with Atmospheric and Oceanic Circulations}

Hubei Province has experienced a significant increase in air temperature of $0.017{ }^{\circ} \mathrm{C}$ year ${ }^{-1}$ ( $p<0.01$ ) during 1961-2015, which is slightly less than the increasing trend in global land surface air temperature of $0.02{ }^{\circ} \mathrm{C}_{\text {year }}{ }^{-1}(p<0.01)$ for the same period [59]. As a result of this significant warming, all warm-related indices present increasing trends, especially for SU25 (0.65 days year ${ }^{-1}$ with $^{-}$ $p<0.01$ ) during 1982-2015. Increasing trends in warm-related indices have also been documented in previous studies that focused on Northwestern China [60], the Yangtze River Basin [17], and mainland China $[4,14]$, which are in line with the global warming. However, increasing trends for many indices in the study area are higher than those for the whole China. For instance, WSDI increases at a rate of 0.22 days year ${ }^{-1}$ in Hubei Province, much higher than the 0.075 days year $^{-1}$ trend for the whole of China for the same period 1961-2015. Owing to the diverse climate, terrains and land cover changes within China, the different trends in temperature indices between the whole China and subregions are generally understandable. Based on multiple datasets from models, satellite images and thermal cameras, Cuxart et al. [61] implied that variability of the air temperature is related to spatial details and scales. In details, the rapid urbanization and land cover changes in the Yangtze River Basin and Central China (e.g., Wuhan) likely lead to a prominent increase in temperature because of surface urban heat islands [62] and changes in surface energy budget [63]. In addition, the trends of all the seven warm-related indices for the period 1982-2015 are much higher than the trends for 1961-2015 (Figure 4), indicating accelerated increases in the temperature extremes and risks in the study area. Based on percentile temperature indices, Fang et al. [14] also found that trends of warm and hot days increased more rapidly after the early 1980s than before the 1980s in most regions in China. Moreover, previous studies demonstrated that indices for nighttime temperature changed much faster than those for the daytime temperature based on global studies $[2,18]$, which was also valid for Hubei Province. Many significant trends at the stations are seen in indices for nighttime temperature (i.e., TN90p and TN10p) but are scarce in daytime temperature indices (i.e., TX90p and TX10p).

As for the precipitation indices, there are no significant trends at the 0.1 significance level for Hubei Province as a whole, except for CWD. This result is consistent with the investigation from neighboring Province (i.e., Hunan Province), where the trends in precipitation extremes at most sites are also insignificant [18]. In addition, our results indicate accelerated changes in precipitation indices, which slightly decrease for extreme precipitation and increase for CDD if comparing trends between 1961-2015 and 1982-2015 (Figure 4). Global warming is expected to increase the moisture holding capacity of the atmosphere, and consequently increase the potential risks from extreme rainfall. In fact, changes in extreme rainfall have spatial variations that extreme rainfall increases typically in coastal regions and might decrease in inland regions (e.g., Hubei Province) [15]. This difference is likely caused by the well-recognized decline in wind speed $[55,56]$. Nevertheless, the extreme precipitation is relatively high in the study area and accounts for up to $40 \%$ of the total annual precipitation in many years, which is expressed as the ratio between R95p and PRCPTOT. Furthermore, based on the CMIP5 models, Pan et al. [64] proposed that all categories of precipitation are projected to increase in frequency over the coming decades.

The temporal variations in these indices are likely influenced by large-scale oceanic and atmospheric circulation oscillations [33]. Here, correlation analyses between the climate indices and the three oceanic and atmospheric indices (i.e., MEI, PDO and AMO) (Table 4) are presented, which follow Shi et al. [4]. Wyatt et al. [65] revealed that the AMO plays an important role in global climate variability as a dominant multidecadal mode of the global climate system. Seven out of 21 indices show significant positive correlations with the AMO index, suggesting that the climate in the study area is most sensitive to the AMO index among the three oceanic and atmospheric climate indices. The warm anomalies of AMO result in extreme warm condition and extreme precipitation in the study area, which is seen from the seven indices in Table 4 . Using a large number of temperature-sensitive proxy 
records, Wang et al. [66] revealed the strong connection between the AMO index and temperature variability in China. The linkage between sea surface temperature anomalies in the North Atlantic and temperature variability over East Asia likely result from two channels, including the mid-latitude westerly anomalies and the propagation of Rossby waves related to the AMO $[4,66]$. Throughout the world, the effects of ENSO variability on temperature extremes have regional differences, which are clearly documented by Kenyon et al. [67]. For Hubei Province, significant correlations $(p<0.1)$ between the four temperature-related indices and MEI are also found. TR20, FD0, and SU35 are positively correlated with MEI, while TX10p and MEI are negatively correlated. The impacts of PDO on climate variability in the study area are very similar to the impacts of ENSO on climate variability. However, almost all the nine precipitation indices are not significantly correlated with the three oceanic and atmospheric climate indices (Table 4). Shi et al. [4] did not find the significant correlations between CDD and CWD precipitation indices and oceanic and the atmospheric climate indices in China and its different regions during 1961-2015, which is in agreement with our result.

Table 4. Correlation coefficients between climatic indicators for the whole study area and circulation modes of climate variability during 1961-2015.

\begin{tabular}{cccc}
\hline Indices & MEI & PDO & AMO \\
\hline SU25 & 0.158 & -0.054 & $0.372^{* *}$ \\
ID0 & -0.061 & -0.148 & -0.040 \\
TR20 & $-0.259^{*}$ & $-0.247^{*}$ & $0.408^{* *}$ \\
FD0 & $-0.252^{*}$ & -0.085 & -0.012 \\
SU35 & $-0.232^{*}$ & $-0.356^{* *}$ & $0.339^{*}$ \\
GSL & 0.055 & 0.008 & 0.060 \\
TN10p & -0.190 & -0.071 & -0.108 \\
TX10p & $0.242^{*}$ & $0.231 *$ & -0.040 \\
TN90p & -0.046 & -0.126 & $0.265^{*}$ \\
TX90p & 0.120 & 0.052 & 0.067 \\
WSDI & 0.078 & -0.066 & $0.529^{* *}$ \\
CSDI & 0.072 & -0.041 & -0.184 \\
SDII & 0.118 & 0.118 & 0.304 \\
R10 & 0.147 & 0.190 & 0.044 \\
R20 & 0.118 & 0.141 & 0.168 \\
R50 & 0.072 & 0.099 & 0.220 \\
CDD & 0.039 & 0.009 & -0.091 \\
CWD & -0.046 & 0.111 & -0.096 \\
R95p & 0.067 & 0.084 & $0.276^{*}$ \\
R99p & 0.017 & -0.010 & $0.310 *$ \\
PRCPTOT & 0.111 & 0.144 & 0.147 \\
\hline
\end{tabular}

Linear trends in all indices were removed before correlation analyses. Significance levels are noted by the following: ${ }^{*} p<0.1$ and ${ }^{* *} p<0.01$

\subsection{Impacts of Climate Indices on the Ecosystem}

To determine the relative sensitivities of the ecosystem indicators to the climate indices, stepwise multiple linear regressions between the 21 climate indices and the three ecosystem variables are carried out at meteorological scales in the study area (see Section 3.4). Generally, the ecosystem variables are more sensitive to temperature indices than precipitation indices (Table 3). Lin et al. [34] also found that mean annual air temperature exerts a stronger effect on the ecosystem than annual total precipitation in Hubei Province over the past decades based on correlation analyses between climatic parameters and ecological indicators. With a new GPP data developed by a machine learning algorithm, the results from Yao et al. [35] reveal that the GPP in Hubei Province is more sensitive to temperature than precipitation and radiation over 1982-2015. This could be explained by the abundant annual precipitation in the study area that causes the regions to not be water deficient for most years [38]. 
The relationships between the three ecosystem variables and the six most sensitive climate factors were built using MLR to further quantify the impacts of the selected indices on interannual variations in the ecosystem for Hubei Province as a whole (Figure 5). To show the spatial sensitivity of the ecosystem to the six indices, spatial patterns of the ecological differences between years with the five highest values and years with the five lowest values for each climate index are calculated (Figure 6). The result of MLR is consistent between NDVI and GPP; both ecosystem variables are most vulnerable to FD0 and R50. In addition, WSDI has the most negative correlations with LAI. Figure 6 further indicates that FD0 and CDD exert the most negative impacts on most regions. In summary, the results reveal the negative effects of FD0, WSDI, R50, and CDD on the ecosystem in Hubei Province integrally or regionally. Based on tree rings and land surface simulations for the 20th century, Rammig et al. [68] also found that hot extremes and dry extremes can trigger exceptional changes in growth or mortality rates of vegetation, which often result in reductions in ecosystem productivity. Although the negative impacts caused by hot extremes and dry extremes on vegetation indices and ecosystem productivity are frequently diagnosed and studied for many places around the world $[23,25,69]$, the potential roles of cold extremes and extreme precipitation are reported less. In addition, our statistical analyses reveal that FD0 and R50 could also reduce ecosystem productivity in Hubei Province. The FD0 in winter of 2008 resulted in an abrupt decrease in NPP in forest and grass ecosystems in Central China [33]. The FD0 could have an influence on the timing of the leaf-out, which consequently causes damage to ecosystems [70]. Many studies demonstrated that extreme precipitation and floods, experienced in the Central China during the past decades, have led to huge disasters and socioeconomic damages $[28,71]$.

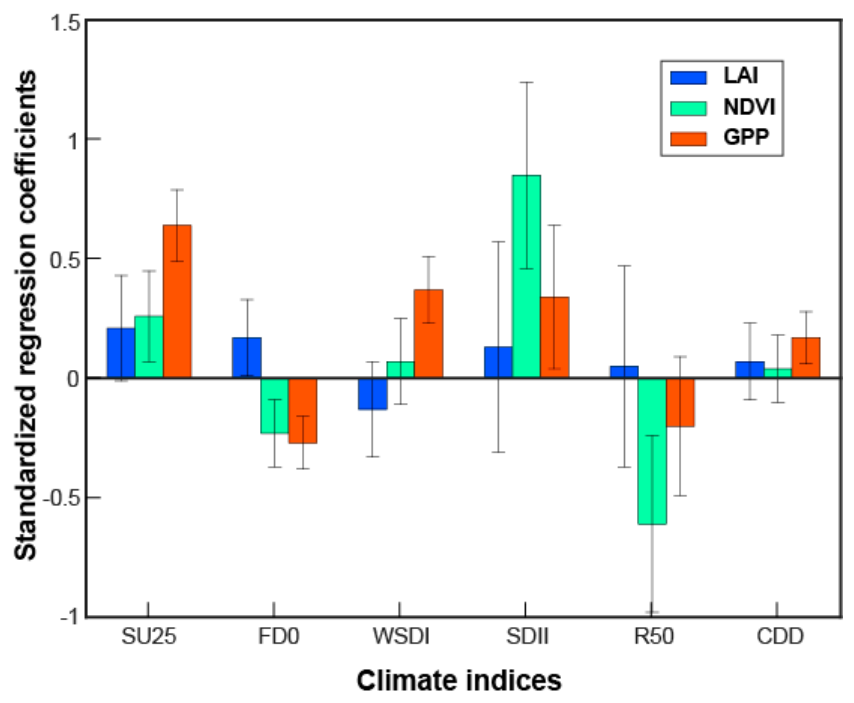

Figure 5. Standardized regression coefficients for the six climate indices in Hubei Province. The error bar represents the standard error for the corresponding regression coefficient in multiple linear regressions.

According to the standardized regression coefficients from MLR, relative contribution rates of the six climate indices to the ecosystem variables were calculated. In addition, we performed MLR with a 10-years-width moving windows, following Wang et al. [29], in order to clarify the temporal evolution of the relative contributions from the selected indices on the ecosystem variables. The positive impacts of SU25 and SDII on all the three ecosystem variables are clearly seen for Hubei Province as a whole and for most areas (Figures 5 and 6). In addition, SU25 solely explains $27.8 \%$ and $32.3 \%$ of the variations in LAI and GPP, respectively, while SDII accounts for $41.1 \%$ of the variations in NDVI among the six climate indices (Table 5). This could be explained that longer SU25 may result in longer growing season [72], and eventually enhance vegetation growth and ecosystem productivity [73]. However, the relative contribution rates of climate indices to interannual variations in the ecosystem 
are temporally unstable and vary considerably (Figure 7). SU25, SDII, and R50 account for the highest relative contribution rates for most years. In addition, the relative contribution rate of SU25 for the three ecosystem variables during the past decade is higher than that during the previous period. In light of Equation (2), we propose that the positive impact of SU25 on the ecosystem will be more remarkable in the future due to the rise in both contribution rate and summer days over time. R50, R95p and R99p have increased during the past decades (Figure 2) and are expected to increase in frequency over the coming decades [64]. As a result, special attention should also be given to the western regions of Hubei Province, where high rapid urbanization makes the region more vulnerable to future precipitation extremes.
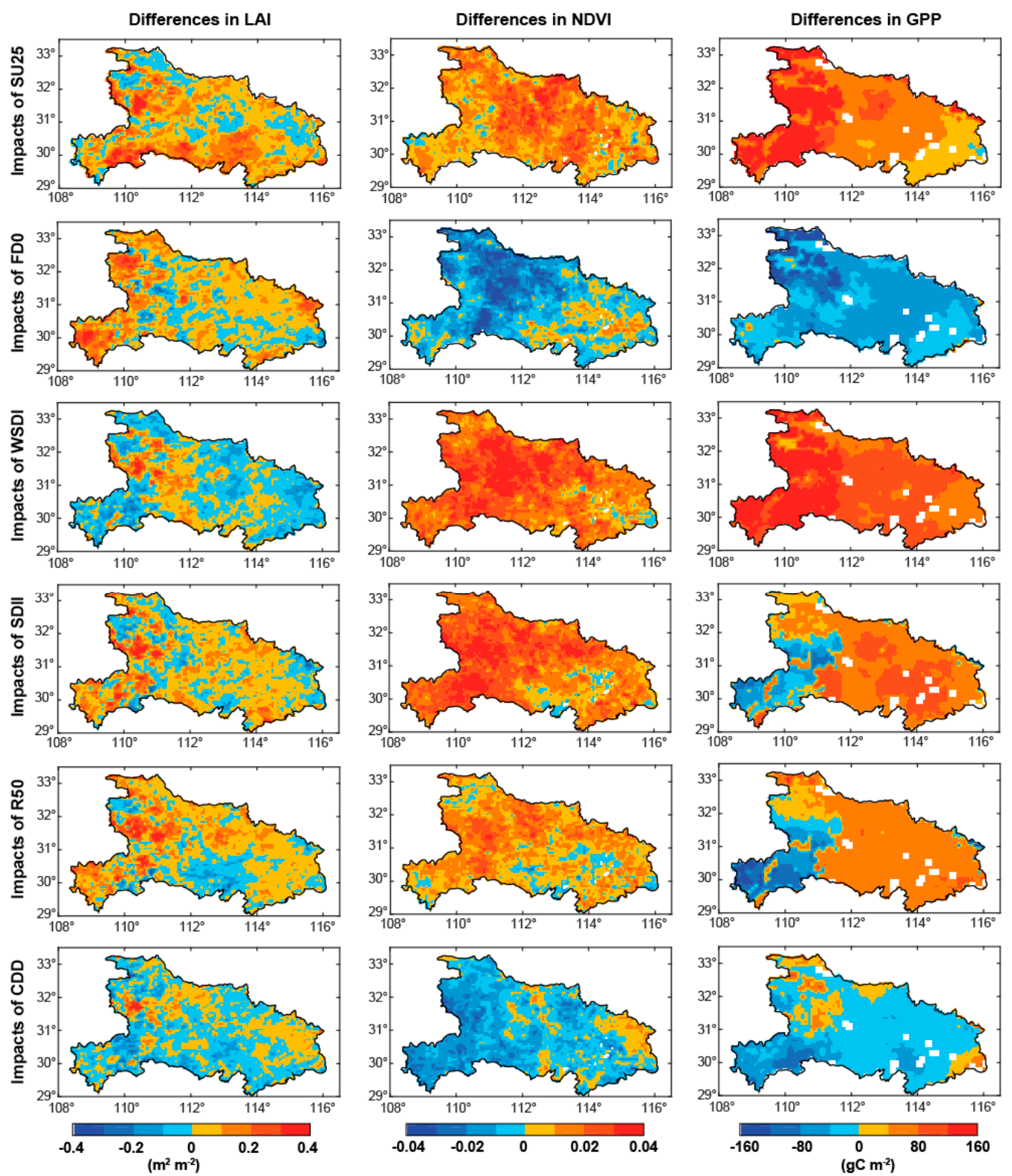

Figure 6. Spatial patterns of the ecological response to changes in the six climate indices. Years with the five highest values (FH) and the five lowest values (FL) in each climate index are chosen as the most significant and insignificant impact years for that climate index, respectively. The impacts are expressed as differences in the ecosystem variables between the selected years for the FH and FL. Notice that linear trends between 1982 and 2015 were removed in each pixel before calculating the differences. 
Table 5. Relative contribution rates (\%) of the six climate indices to ecosystem variables in Hubei Province.

\begin{tabular}{ccccccc}
\hline Variables & SU25 & FD0 & WSDI & SDII & R50 & CDD \\
\hline LAI & $27.8^{*}$ & 22.1 & 16.6 & 17.5 & 6.4 & 9.6 \\
NDVI & 12.9 & 11.2 & 3.3 & $41.1^{*}$ & 29.4 & 2.1 \\
GPP & $32.3^{*}$ & 13.4 & 18.7 & 17.2 & 10 & 8.4 \\
\hline
\end{tabular}

* The maximum values of the contribution rate for each ecosystem variable are marked.
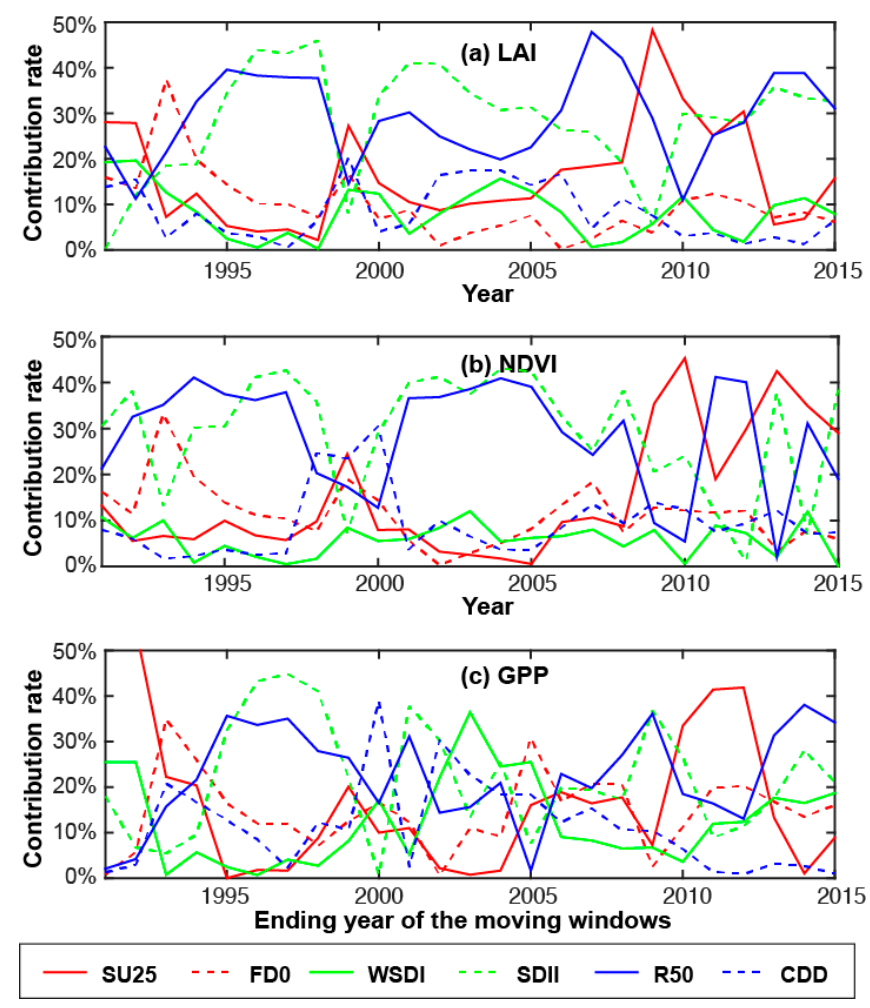

Figure 7. Temporal evolution of the relative contribution rate of the six climate indices to (a) LAI, (b) NDVI, and (c) GPP, respectively.

\subsection{Uncertainties and Perspectives}

Uncertainties may still exist when analyzing the relation between ecosystems and climate extremes, as well as the relation between climate extremes and large-scale oceanic and atmospheric circulation oscillations. Since the climate datasets and the method to extract the climate extremes are robust, the uncertainties may firstly result from the ecosystem variables. For example, although some improvements have been made from an increase in eddy flux sites and updated climate data, large uncertainties still exist in GPP data [35]. Secondly, different resolutions between ground observation and satellite-derived data might introduce uncertainties in the correlation analysis between climate and vegetation indices at the site scale. Simó et al. [74] indicated that there is a bias between in situ data and satellite-derived pixel average in a heterogeneous area. Thirdly, other factors may also influence ecosystems, such as $\mathrm{CO}_{2}$ fertilization effects [9], nitrogen deposition and interference from human activities (e.g., land cover change) [75]. However, these factors are more likely to cause long-term trends in ecosystem variables, which are beyond the scope of this study. In addition, the removal of linear trend and the performance of MLR with a temporal moving window can further eliminate the effects from these long-term factors and enhance the climate-induced interannual variations in the ecosystem variables to some extent. Nevertheless, the ecological response to climate extremes at larger spatial scales, combined with other factors, should be comprehensively investigated in the future 
studies. Finally, we have also found several discrepancies between climate extremes and atmospheric and oceanic climate indices at annual time scale. For instance, the precipitation extremes in 1998 in the study area, which are shown by R50, R95p, and R99p extreme precipitation indices, correspond to the high values of MEI and PDO in 1997. In fact, comprehensive analyses between consecutive days with precipitation extremes in China and oceanic and atmospheric climate indices have also not found expected connections [4]. This possibly indicates a monthly delayed responses of regional climate extremes to large-scale oceanic and atmospheric circulation oscillations (e.g., MEI), which could not be captured by the yearly data. We leave this delayed response of climate extremes for a further study.

\section{Conclusions}

In this study, we evaluated the variabilities of climate extremes and their impacts on vegetation variabilities in Hubei Province. Up to 21 climate indices were calculated using daily temperature and precipitation meteorological data during 1961-2015. Remarkable increasing trends in all of the warm-related indices were presented. Spatially, extreme precipitation showed increasing trends in the eastern regions and downtrends in the western regions. Accelerated changes in most indices were diagnosed when we compared trends between the period of 1982-2015 and 1961-2015. In addition, correlation analyses between climate indices and oceanic and atmospheric climate indices demonstrated that the climate in Hubei Province was more sensitive to the AMO index than ENSO and PDO. The warm anomalies of AMO lead to extreme warm conditions and extreme precipitation in the study area.

Systematic statistical analyses were applied to quantifying the sensitivity of the ecosystem to climate indices. Based on stepwise linear regressions, we found three precipitation indices and three temperature indices (i.e., SU25, FD0, WSDI, SDII, R50, and CDD), which were mostly correlated with the three ecosystem variables at the site scale. Among these six indices, the negative impacts caused by FD0, WSDI, R50, and CDD on the ecosystem were clearly seen in Hubei Province integrally or regionally. Furthermore, the positive impact of SU25 on the ecosystem will be more remarkable in the future due to the increase in both contribution rate and summer days over time. Since extreme precipitation accounts for a large amount of yearly precipitation and is likely to increase over the coming decades, the ecosystem in Hubei might be more vulnerable to future precipitation extremes.

In sum, this study suggests that vegetation could benefit from rapid increases in SU25 in the future. And we propose that more concerns should be given to FD0, WSDI, R50, and CDD because of the mainly negative impacts on the ecosystem in the study area. Our study emphasizes the importance of comprehensively quantifying different climate index impacts on regional terrestrial ecosystems. These results may have policy implications for the adaptations to extreme climate events.

Acknowledgments: This study was financially supported by the Natural Science Foundation for Distinguished Young Scholars of Hubei Province of China (2016CFA051), the National Natural Science Foundation of China (No. 41772029, 41322013 and 41601044), the 111 Project (No. B14031 and B08030), and the Special Fund for Basic Scientific Research of Central Colleges, China University of Geosciences, Wuhan (No. CUG15063). We would like to thank Yitong Yao from Peking University for sharing GPP data with us.

Author Contributions: Weizhe Chen, Chunju Huang, and Lunche Wang designed the research; Weizhe Chen and Dongmei Li collected and analyzed the data; Weizhe Chen wrote the manuscript; and Weizhe Chen, Chunju Huang, Lunche Wang, and Dongmei Li revised the manuscript.

Conflicts of Interest: The authors declare no conflict of interest.

\section{References}

1. Intergovernmental Panel on Climate Change (IPCC). Climate Change 2013: The Physical Science Basis. Contribution of Working Group I to the Fifth Assessment Report of the Intergovernmental Panel on Climate Change; Cambridge University Press: Cambridge, UK; New York, NY, USA, 2013. 
2. Alexander, L.V.; Zhang, X.; Peterson, T.C.; Caesar, J.; Gleason, B.; Klein Tank, A.M.G.; Haylock, M.; Collins, D.; Trewin, B.; Rahimzadeh, F.; et al. Global observed changes in daily climate extremes of temperature and precipitation. J. Geophys. Res. 2006, 111, 1042-1063. [CrossRef]

3. Shrestha, A.B.; Bajracharya, S.R.; Sharma, A.R.; Duo, C.; Kulkarni, A. Observed trends and changes in daily temperature and precipitation extremes over the Koshi river basin 1975-2010. Int. J. Climatol. 2017, 37, 1066-1083. [CrossRef]

4. Shi, J.; Cui, L.; Wen, K.; Tian, Z.; Wei, P.; Zhang, B. Trends in the consecutive days of temperature and precipitation extremes in China during 1961-2015. Environ. Res. 2018, 161, 381-391. [CrossRef] [PubMed]

5. Ciais, P.; Reichstein, M.; Viovy, N.; Granier, A.; Ogee, J.; Allard, V.; Aubinet, M.; Buchmann, N.; Bernhofer, C.; Carrara, A.; et al. Europe-wide reduction in primary productivity caused by the heat and drought in 2003. Nature 2005, 437, 529-533. [CrossRef] [PubMed]

6. Intergovernmental Panel on Climate Change (IPCC). Managing the Risks of Extreme Events and Disasters to Advance Climate Change Adaption; Cambridge University Press: Cambridge, UK, 2012.

7. Zscheischler, J.; Mahecha, M.D.; Von Buttlar, J.; Harmeling, S.; Jung, M.; Rammig, A.; Randerson, J.T.; Schölkopf, B.; Seneviratne, S.I.; Tomelleri, E. A few extreme events dominate global interannual variability in gross primary production. Environ. Res. Lett. 2014, 9, 035001. [CrossRef]

8. Donat, M.; Alexander, L.; Yang, H.; Durre, I.; Vose, R.; Caesar, J. Global Land-Based Datasets for Monitoring Climatic Extremes. Bull. Am. Meteorol. Soc. 2013, 94, 997-1006. [CrossRef]

9. Zhu, Z.C.; Piao, S.L.; Myneni, R.B.; Huang, M.T.; Zeng, Z.Z.; Canadell, J.G.; Ciais, P.; Sitch, S.; Friedlingstein, P.; Arneth, A.; et al. Greening of the Earth and its drivers. Nat. Clim. Chang. 2016, 6, 791-795. [CrossRef]

10. Garcia, R.A.; Cabeza, M.; Rahbek, C.; Araujo, M.B. Multiple dimensions of climate change and their implications for biodiversity. Science 2014, 344, 1247579. [CrossRef] [PubMed]

11. Caesar, J.; Alexander, L.; Vose, R. Large-scale changes in observed daily maximum and minimum temperatures: Creation and analysis of a new gridded data set. J. Geophys. Res. 2006, 111, 854-871. [CrossRef]

12. Peterson, T.C.; Manton, M.J. Monitoring changes in climate extremes - A tale of international collaboration. Bull. Am. Meteorol. Soc. 2008, 89, 1266-1271. [CrossRef]

13. Donat, M.G.; Alexander, L.V.; Yang, H.; Durre, I.; Vose, R.; Dunn, R.J.H.; Willett, K.M.; Aguilar, E.; Brunet, M.; Caesar, J.; et al. Updated analyses of temperature and precipitation extreme indices since the beginning of the twentieth century: The HadEX2 dataset. J. Geophys. Res. 2013, 118, 2098-2118. [CrossRef]

14. Fang, S.B.; Qi, Y.; Han, G.J.; Li, Q.X.; Zhou, G.S. Changing Trends and Abrupt Features of Extreme Temperature in Mainland China from 1960 to 2010. Atmosphere 2016, 7, 22. [CrossRef]

15. Xiao, C.; Wu, P.; Zhang, L.; Song, L. Robust increase in extreme summer rainfall intensity during the past four decades observed in China. Sci. Rep. 2016, 6, 38506. [CrossRef] [PubMed]

16. Wang, Y.Q.; Zhou, L. Observed trends in extreme precipitation events in China during 1961-2001 and the associated changes in large-scale circulation. Geophys. Res. Lett. 2005, 32. [CrossRef]

17. Guan, Y.H.; Zhang, X.C.; Zheng, F.L.; Wang, B. Trends and variability of daily temperature extremes during 1960-2012 in the Yangtze River Basin, China. Glob. Planet. Chang. 2015, 124, 79-94. [CrossRef]

18. Chen, A.; He, X.; Guan, H.; Cai, Y. Trends and periodicity of daily temperature and precipitation extremes during 1960-2013 in Hunan Province, central south China. Theor. Appl. Climatol. 2017, 1-18. [CrossRef]

19. Wang, H.J.; Sun, J.Q.; Chen, H.P.; Zhu, Y.L.; Zhang, Y.; Jiang, D.B.; Lang, X.M.; Fan, K.; Yu, E.T.; Yang, S. Extreme Climate in China: Facts, Simulation and Projection. Meteorol. Z. 2012, 21, 279-304. [CrossRef]

20. Xu, C.H.; Luo, Y.; Xu, Y. Projected changes of precipitation extremes in river basins over China. Quat. Int. 2011, 244, 149-158. [CrossRef]

21. Niu, X.; Wang, S.; Tang, J.; Lee, D.K.; Gutowski, W.; Dairaku, K.; McGregor, J.; Katzfey, J.; Gao, X.; Wu, J. Ensemble evaluation and projection of climate extremes in China using RMIP models. Int. J. Climatol. 2018, 38, 2039-2055. [CrossRef]

22. Sun, Q.H.; Miao, C.Y.; Duan, Q.Y. Extreme climate events and agricultural climate indices in China: CMIP5 model evaluation and projections. Int. J. Climatol. 2016, 36, 43-61. [CrossRef]

23. Doughty, C.E.; Metcalfe, D.B.; Girardin, C.A.; Amezquita, F.F.; Cabrera, D.G.; Huasco, W.H.; Silva-Espejo, J.E.; Araujo-Murakami, A.; da Costa, M.C.; Rocha, W.; et al. Drought impact on forest carbon dynamics and fluxes in Amazonia. Nature 2015, 519, 78-82. [CrossRef] [PubMed] 
24. Holmgren, M.; Hirota, M.; van Nes, E.H.; Scheffer, M. Effects of interannual climate variability on tropical tree cover. Nat. Clim. Chang. 2013, 3, 755-758. [CrossRef]

25. Yuan, W.; Cai, W.; Chen, Y.; Liu, S.; Dong, W.; Zhang, H.; Yu, G.; Chen, Z.; He, H.; Guo, W.; et al. Severe summer heatwave and drought strongly reduced carbon uptake in Southern China. Sci. Rep. 2016, 6, 18813. [CrossRef] [PubMed]

26. Xu, Y.; Shen, Z.H.; Ying, L.X.; Ciais, P.; Liu, H.Y.; Piao, S.L.; Wen, C.; Jiang, Y.X. The exposure, sensitivity and vulnerability of natural vegetation in China to climate thermal variability (1901-2013): An indicator-based approach. Ecol. Indic. 2016, 63, 258-272. [CrossRef]

27. Piao, S.; Ciais, P.; Huang, Y.; Shen, Z.; Peng, S.; Li, J.; Zhou, L.; Liu, H.; Ma, Y.; Ding, Y.; et al. The impacts of climate change on water resources and agriculture in China. Nature 2010, 467, 43-51. [CrossRef] [PubMed]

28. Duan, W.L.; He, B.; Nover, D.; Fan, J.L.; Yang, G.S.; Chen, W.; Meng, H.F.; Liu, C.M. Floods and associated socioeconomic damages in China over the last century. Nat. Hazards 2016, 82, 401-413. [CrossRef]

29. Wang, Z.L.; Xie, P.W.; Lai, C.G.; Chen, X.H.; Wu, X.S.; Zeng, Z.Y.; Li, J. Spatiotemporal variability of reference evapotranspiration and contributing climatic factors in China during 1961-2013. J. Hydrol. 2017, 544, 97-108. [CrossRef]

30. Rao, B.B.; Chowdary, P.S.; Sandeep, V.M.; Rao, V.U.M.; Venkateswarlu, B. Rising minimum temperature trends over India in recent decades: Implications for agricultural production. Glob. Planet. Chang. 2014, 117, $1-8$.

31. Seddon, A.W.; Macias-Fauria, M.; Long, P.R.; Benz, D.; Willis, K.J. Sensitivity of global terrestrial ecosystems to climate variability. Nature 2016, 531, 229-232. [CrossRef] [PubMed]

32. Beer, C.; Reichstein, M.; Tomelleri, E.; Ciais, P.; Jung, M.; Carvalhais, N.; Rodenbeck, C.; Arain, M.A.; Baldocchi, D.; Bonan, G.B.; et al. Terrestrial gross carbon dioxide uptake: Global distribution and covariation with climate. Science 2010, 329, 834-838. [CrossRef] [PubMed]

33. Liu, Y.; Yu, D.; Su, Y.; Hao, R. Quantifying the effect of trend, fluctuation, and extreme event of climate change on ecosystem productivity. Environ. Monit. Assess. 2014, 186, 8473-8486. [CrossRef] [PubMed]

34. Lin, A.W.; Zhu, H.J.; Wang, L.C.; Gong, W.; Zou, L. Characteristics of Long-Term Climate Change and the Ecological Responses in Central China. Earth Interact. 2016, 20, 1-24. [CrossRef]

35. Yao, Y.; Wang, X.; Li, Y.; Wang, T.; Shen, M.; Du, M.; He, H.; Li, Y.; Luo, W.; Ma, M.; et al. Spatiotemporal pattern of gross primary productivity and its covariation with climate in China over the last thirty years. Glob. Chang. Biol. 2017, 24, 184-196. [CrossRef] [PubMed]

36. Wang, L.; Gong, W.; Ma, Y.; Hu, B.; Zhang, M. Photosynthetically active radiation and its relationship with global solar radiation in Central China. Int. J. Biometeorol. 2014, 58, 1265-1277. [CrossRef] [PubMed]

37. Cai, Y.J.; Tan, L.C.; Cheng, H.; An, Z.S.; Edwards, R.L.; Kelly, M.J.; Kong, X.G.; Wang, X.F. The variation of summer monsoon precipitation in central China since the last deglaciation. Earth Planet. Sci. Lett. 2010, 291, 21-31. [CrossRef]

38. Chen, J.; Wu, X.D.; Finlayson, B.L.; Webber, M.; Wei, T.Y.; Li, M.T.; Chen, Z.Y. Variability and trend in the hydrology of the Yangtze River, China: Annual precipitation and runoff. J. Hydrol. 2014, 513, 403-412. [CrossRef]

39. China Meteorological Administration. Available online: http:/ / data.cma.cn/ (accessed on 11 January 2018).

40. Earth System Research Laboratory, National Oceanic and Atmospheric Administration. Available online: http:/ / www.esrl.noaa.gov/psd/data/climateindices/list/ (accessed on 11 January 2018).

41. Global Mapping Leaf Area Index Product. Available online: http://www.globalmapping.org/ (accessed on 11 January 2018).

42. Third-Generation Normalized Difference Vegetation Index Product. Available online: https://nex.nasa.gov / nex/projects/1349/ (accessed on 11 January 2018).

43. Liu, Y.; Liu, R.; Chen, J.M. Retrospective retrieval of long-term consistent global leaf area index (1981-2011) from combined AVHRR and MODIS data. J. Geophys. Res. 2012, 117. [CrossRef]

44. Pinzon, J.; Tucker, C. A Non-Stationary 1981-2012 AVHRR NDVI3g Time Series. Remote Sens. 2014, 6, 6929-6960. [CrossRef]

45. Liu, M.X.; Xu, X.L.; Sun, A. Decreasing spatial variability in precipitation extremes in southwestern China and the local/large-scale influencing factors. J. Geophys. Res. 2015, 120, 6480-6488. [CrossRef] 
46. Shen, M.G.; Zhang, G.X.; Cong, N.; Wang, S.P.; Kong, W.D.; Piao, S.L. Increasing altitudinal gradient of spring vegetation phenology during the last decade on the Qinghai-Tibetan Plateau. Agric. For. Meteorol. 2014, 189, 71-80. [CrossRef]

47. Liu, G.; Liu, H.Y.; Yin, Y. Global patterns of NDVI-indicated vegetation extremes and their sensitivity to climate extremes. Environ. Res. Lett. 2013, 8, 279-288. [CrossRef]

48. Liang, K.; Bai, P.; Li, J.J.; Liu, C.M. Variability of temperature extremes in the Yellow River basin during 1961-2011. Quat. Int. 2014, 336, 52-64. [CrossRef]

49. Subash, N.; Singh, S.S.; Priya, N. Extreme rainfall indices and its impact on rice productivity-A case study over sub-humid climatic environment. Agric. Water Manag. 2011, 98, 1373-1387. [CrossRef]

50. Zhang, X.B.; Hegerl, G.; Zwiers, F.W.; Kenyon, J. Avoiding inhomogeneity in percentile-based indices of temperature extremes. J. Clim. 2005, 18, 1641-1651. [CrossRef]

51. Hyndman, R.J.; Fan, Y.N. Sample quantiles in statistical packages. Am. Stat. 1996, 50, 361-365.

52. Wang, L.C.; Kisi, O.; Zounemat-Kermani, M.; Li, H. Pan evaporation modeling using six different heuristic computing methods in different climates of China. J. Hydrol. 2017, 544, 407-427. [CrossRef]

53. Bai, F.; Sang, W.G.; Axmacher, J.C. Forest vegetation responses to climate and environmental change: A case study from Changbai Mountain, NE China. For. Ecol. Manag. 2011, 262, 2052-2060. [CrossRef]

54. Thiessen, A.H. Precipitation averages for large areas. Mon. Weather Rev. 1911, 39, 1082-1084. [CrossRef]

55. Guo, H.; Xu, M.; Hu, Q. Changes in near-surface wind speed in China: 1969-2005. Int. J. Climatol. 2011, 31, 349-358. [CrossRef]

56. McVicar, T.R.; Roderick, M.L.; Donohue, R.J.; Li, L.T.; Van Niel, T.G.; Thomas, A.; Grieser, J.; Jhajharia, D.; Himri, Y.; Mahowald, N.M.; et al. Global review and synthesis of trends in observed terrestrial near-surface wind speeds: Implications for evaporation. J. Hydrol. 2012, 416-417, 182-205. [CrossRef]

57. Piao, S.; Yin, G.; Tan, J.; Cheng, L.; Huang, M.; Li, Y.; Liu, R.; Mao, J.; Myneni, R.B.; Peng, S.; et al. Detection and attribution of vegetation greening trend in China over the last 30 years. Glob. Chang. Biol. 2015, 21, 1601-1609. [CrossRef] [PubMed]

58. Gong, W.; Wang, L.C.; Lin, A.W.; Zhang, M. Evaluating the monthly and interannual variation of net primary production in response to climate in Wuhan during 2001 to 2010. Geosci. J. 2012, 16, 347-355. [CrossRef]

59. Hansen, J.; Ruedy, R.; Sato, M.; Lo, K. Global Surface Temperature Change. Rev. Geophys. 2010, 48. [CrossRef]

60. Lin, P.; He, Z.; Du, J.; Chen, L.; Zhu, X.; Li, J. Recent changes in daily climate extremes in an arid mountain region, a case study in northwestern China's Qilian Mountains. Sci. Rep. 2017, 7, 2245. [CrossRef] [PubMed]

61. Cuxart, J.; Wrenger, B.; Martínezvillagrasa, D.; Reuder, J.; Jonassen, M.O.; Jiménez, M.A.; Lothon, M.; Lohou, F.; Hartogensis, O.; Dünnermann, J. Estimation of the advection effects induced by surface heterogeneities in the surface energy budget. Atmos. Chem. Phys. 2016, 14, 1-16.

62. Yao, R.; Wang, L.; Huang, X.; Niu, Z.; Liu, F.; Wang, Q. Temporal trends of surface urban heat islands and associated determinants in major Chinese cities. Sci. Total Environ. 2017, 609, 742-754. [CrossRef] [PubMed]

63. Peng, S.S.; Piao, S.; Zeng, Z.; Ciais, P.; Zhou, L.; Li, L.Z.; Myneni, R.B.; Yin, Y.; Zeng, H. Afforestation in China cools local land surface temperature. Proc. Natl. Acad. Sci. USA 2014, 111, 2915-2919. [CrossRef] [PubMed]

64. Pan, Z.T.; Zhang, Y.J.; Liu, X.D.; Gao, Z.Q. Current and future precipitation extremes over Mississippi and Yangtze River basins as simulated in CMIP5 models. J. Earth Sci. 2016, 27, 22-36. [CrossRef]

65. Wyatt, M.G.; Kravtsov, S.; Tsonis, A.A. Atlantic Multidecadal Oscillation and Northern Hemisphere's climate variability. Clim. Dyn. 2012, 38, 929-949. [CrossRef]

66. Wang, J.; Yang, B.A.O.; Ljungqvist, F.C.; Zhao, Y.A.N. The relationship between the Atlantic Multidecadal Oscillation and temperature variability in China during the last millennium. J. Quat. Sci. 2013, 28, 653-658. [CrossRef]

67. Kenyon, J.; Hegerl, G.C. Influence of Modes of Climate Variability on Global Precipitation Extremes. J. Clim. 2010, 23, 6248-6262. [CrossRef]

68. Rammig, A.; Wiedermann, M.; Donges, J.F.; Babst, F.; von Bloh, W.; Frank, D.; Thonicke, K.; Mahecha, M.D. Coincidences of climate extremes and anomalous vegetation responses: Comparing tree ring patterns to simulated productivity. Biogeosciences 2015, 12, 373-385. [CrossRef]

69. Lesk, C.; Rowhani, P.; Ramankutty, N. Influence of extreme weather disasters on global crop production. Nature 2016, 529, 84-87. [CrossRef] [PubMed]

70. Polgar, C.A.; Primack, R.B. Leaf-out phenology of temperate woody plants: From trees to ecosystems. New Phytol. 2011, 191, 926-941. [CrossRef] [PubMed] 
71. Wang, L.; Gu, W. The Eastern China flood of June 2015 and its causes. Sci. Bull. 2016, 61, 178-184. [CrossRef]

72. Cong, N.; Wang, T.; Nan, H.; Ma, Y.; Wang, X.; Myneni, R.B.; Piao, S. Changes in satellite-derived spring vegetation green-up date and its linkage to climate in China from 1982 to 2010: A multimethod analysis. Glob. Chang. Biol. 2013, 19, 881-891. [CrossRef] [PubMed]

73. Piao, S.L.; Friedlingstein, P.; Ciais, P.; Viovy, N.; Demarty, J. Growing season extension and its impact on terrestrial carbon cycle in the Northern Hemisphere over the past 2 decades. Glob. Biogeochem. Cycles 2007, 21. [CrossRef]

74. Simó, G.; Garcíasantos, V.; Jiménez, M.; Martínezvillagrasa, D.; Picos, R.; Caselles, V.; Cuxart, J. Landsat and Local Land Surface Temperatures in a Heterogeneous Terrain Compared to MODIS Values. Remote Sens. 2016, 8, 849. [CrossRef]

75. Zhang, Y.L.; Song, C.H.; Zhang, K.R.; Cheng, X.L.; Band, L.E.; Zhang, Q.F. Effects of land use/land cover and climate changes on terrestrial net primary productivity in the Yangtze River Basin, China, from 2001 to 2010. J. Geophys. Res. 2014, 119, 1092-1109. [CrossRef]

(C) 2018 by the authors. Licensee MDPI, Basel, Switzerland. This article is an open access article distributed under the terms and conditions of the Creative Commons Attribution (CC BY) license (http:// creativecommons.org/licenses/by/4.0/). 